\title{
Late-onset diaphragmatic hernia after percutaneous radiofrequency ablation of hepatocellular carcinoma: a case study
}

\author{
Tomoyuki Abe ${ }^{1}$, Hironobu Amano ${ }^{1}$, Hitomi Takechi ${ }^{1}$, Nobuaki Fujikuni ${ }^{1}$, Tatsunari Sasada ${ }^{1}$, Makoto Yoshida ${ }^{1}$, \\ Minoru Yamaki ${ }^{1}$, Masahiro Nakahara ${ }^{1}$ and Toshio Noriyuki ${ }^{1,2^{*}}$
}

\begin{abstract}
Percutaneous radiofrequency ablation (RFA) is widely used as an effective treatment of liver tumors. Several reported complications associated with RFA are due to thermal damage of neighboring organs. The present report presents a case of diaphragmatic hernia associated with RFA and hepatocellular carcinoma (HCC). A 72-year-old woman with S5 and 88 HCCs was treated repeatedly with RFA and transcatheter arterial chemoembolization for 3 years. After the third course of RFA to target the recurring S5 HCC, acute abdominal pain and dyspnea suddenly occurred. Contrast-enhanced computed tomography revealed intrusion of the transverse colon through the right diaphragmatic hernia. In addition, the colon was dilated and showed changes suggestive of ischemic conditions. An emergency surgery was performed to close the hernia by using non-absorbable sutures to preserve the colon. The patient was discharged without any complications 13 days after the surgery. The first-line treatment of this disease involves surgical intervention. Diaphragmatic hernia is a rare complication of RFA. The present case suggests that patients who undergo several rounds of RFA require surveillance for diaphragmatic hernias.
\end{abstract}

Keywords: Diaphragmatic hernia, Hepatocellular carcinoma, Radiofrequency ablation

\section{Background}

The incidence of hepatocellular carcinoma (HCC) has been increasing worldwide, making $\mathrm{HCC}$ one of the most common malignant tumors [1]. Liver resection provides enhanced long-term survival, with a 5-year overall survival rate of around $60 \%[2,3]$. These results are reflected by developments in the surgical techniques and perioperative management approaches for HCC. Liver resection is the first-line intervention for patients with preserved liver function and fewer than three liver tumors. Alternative treatments include radiofrequency ablation (RFA) and transarterial chemoembolization (TACE). RFA is widely accepted as a minimally invasive treatment of $\mathrm{HCC}$, with low risk of complications,

\footnotetext{
* Correspondence: nori0509@hotmail.co.jp

'Department of Surgery, Onomichi General Hospital, Onomichi, Hiroshima, Japan

${ }^{2}$ Department of Gastroenterological and Transplant Surgery, Applied Life Sciences, Institute of Biomedical and Health Sciences, Hiroshima University, Hiroshima, Japan
}

\section{说) Springer}

(c) 2016 Abe et al. Open Access This article is distributed under the terms of the Creative Commons Attribution 4.0 International License (http://creativecommons.org/licenses/by/4.0/), which permits unrestricted use, distribution, and reproduction in any medium, provided you give appropriate credit to the original author(s) and the source, provide a link to the Creative Commons license, and indicate if changes were made.

\section{Case presentation}

A 72-year-old woman was admitted to our hospital because of acute pain in the right hypochondrium. In 2011, she was diagnosed with hepatitis C virus-related liver cirrhosis (Child-Pugh grade B) and HCC. RFA and TACE were first introduced for S5 HCC. After the first treatment, the HCC did not recur; however, S5 HCC recurrence was detected on dynamic computed tomography (CT) in September 2013. Follow-up CT was performed every 3 months after the RFA. After several 


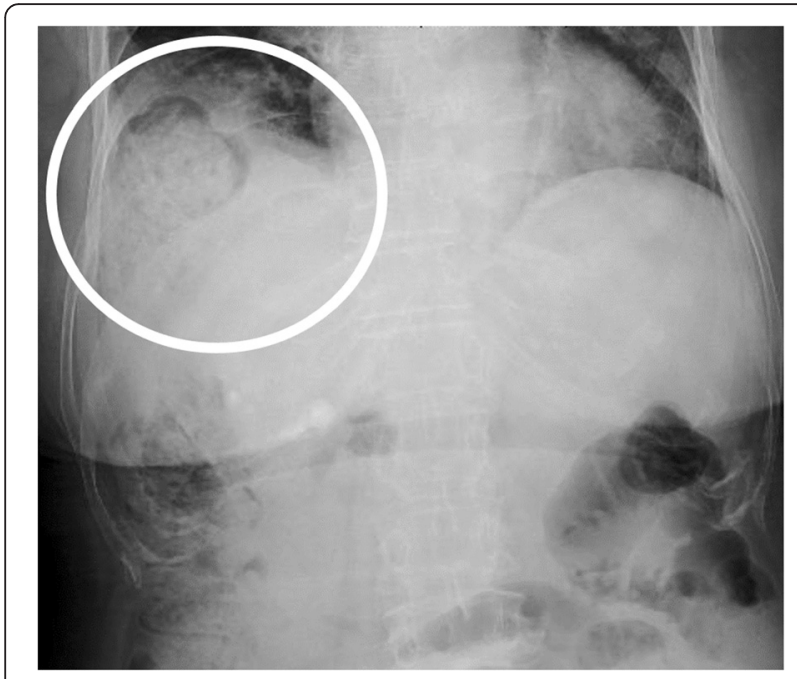

Fig. 1 Abdominal radiograph obtained at symptom onset, showing the deviation of the colon across the right diaphragm (white circle)

courses of RFA therapy targeting the recurring HCC, a sudden, strong right upper abdominal pain and dyspnea occurred in 2015. The last RFA therapy session was performed 15 months before the symptom onset. Abdominal radiography revealed a massive abnormal free air on the right side under the diaphragm (Fig. 1). Hence, the patient was transferred to our hospital under the suspicion of acute abdomen. The vital signs were not remarkable as follows: blood pressure, 136/ $90 \mathrm{mmHg}$; pulse rate, $107 / \mathrm{min}$; and $\mathrm{SpO}_{2}, 96 \%$ (room air). In a physical examination, acute pain was found in the right hypochondrium. Laboratory findings did not demonstrate any abnormalities, including white blood cell count or C-reactive protein level. Chest radiograms showed lower right pulmonary opacity and left mediastinal shift. Contrast-enhanced CT revealed that the transverse colon was intruded through a diaphragmatic hernia and the colon was well enhanced (Fig. 2a, b). As the diagnosis included a right diaphragmatic hernia with suspicion of a strained colon, an emergency surgery was performed. The surgery revealed a transverse colon inserted in the right pleural cavity via the diaphragmatic hernia, which was $10 \mathrm{~cm}$ in diameter (Fig. 3). The location of the RFA-treated tumor matched the site of the diaphragmatic hernia. The intruded transverse colon did not show necrosis. Thus, after dissolving the hernial intrusion, the hernia was simply closed by using nonabsorbable sutures. The overall surgery time was $85 \mathrm{~min}$, and the amount of bleeding was $650 \mathrm{ml}$. After the surgery, the patient was discharged without any complications.

Diaphragmatic hernia is a rare late-onset complication associated with RFA. Repetitive RFA for HCC makes the diaphragm fragile due to thermal damage $[6,9]$. The present case required an emergency surgery because the transverse colon was intubated through the diaphragmatic hernia. After three courses of RFA, contrastenhanced CT revealed the sudden emergence of a right diaphragmatic hernia. Shibuya et al. suggested the rarity of late-onset diaphragmatic hernia, highlighting that only six cases of RFA-related iatrogenic diaphragmatic hernia have been reported [10]. Recent reports have shown that laparoscopic methods of diaphragmatic repair have been effective in elective settings [7]. The surgical approach could depend on the timing of the surgery and the association with other organ intrusions of the hernia, making it difficult to obtain a working space for laparoscopic repair. To prevent additional damage due to hernial intrusion, this disease should be treated as soon as diagnosis is confirmed.

In general, according to liver function and tumor stage, percutaneous treatment is selected for local liver tumors; however, its efficacy could not match to that of
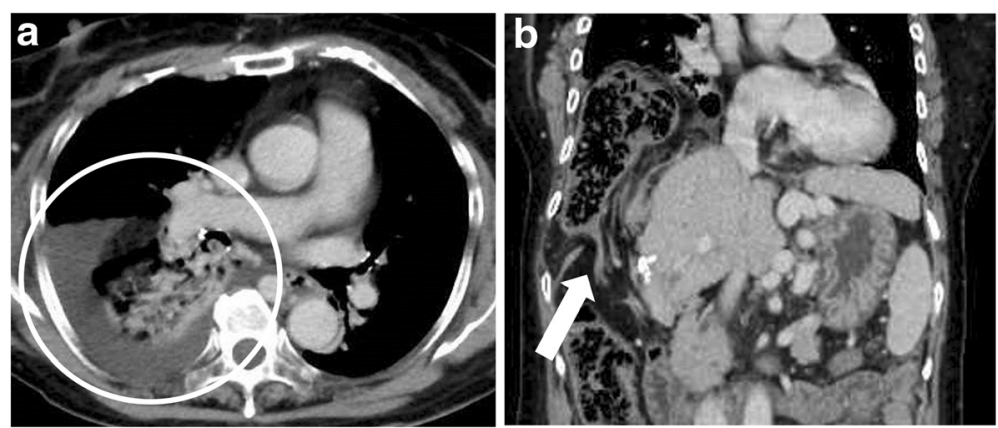

Fig. 2 a The transverse colon is inserted in the right pleural cavity through the diaphragmatic hernia. The hernia is $10 \mathrm{~cm}$ in diameter. Pleural effusion is detected in the right chest cavity (white circle). b The massive transverse colon is intruded into the right chest cavity. Severe stricture can be observed (white arrow) 


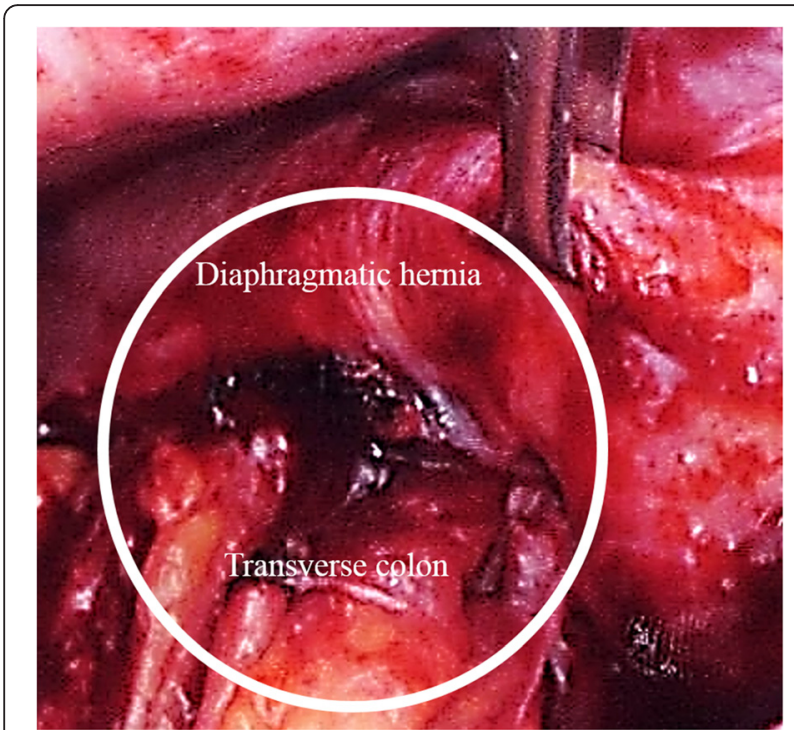

Fig. 3 The transverse colon is directly intruded into the right thoracic cavity through the diaphragmatic hernia (white circle)

other methods such as LR and liver transplantation [5, 11]. Percutaneous RFA treatment was established as a promising therapy to maintain local liver malignancy; however, both acute and late-onset complications have been reported $[12,13]$. In a study conducted in Italy, 2320 patients with 3554 lesions were enrolled, of whom 1610 patients had HCC with abnormal liver disease. Of the 1610 patients, six died owing to complications, including intestinal perforation, septic shock, tumor rupture, liver failure, and other unknown causes [9]. Major complications were intraperitoneal hemorrhage and intrahepatic abscess. RFA complications were subdivided into four categories as follows: thermal damage from heating and mechanical, septic, and other unexplained causes [6]. Regarding diaphragmatic hernia, only six cases associated with RFA have been reported (Table 1) $[7,10,14-17]$. Of these cases, one was treated conservatively and the rest required surgical intervention.
Preventing this complication is impossible, but early diagnosis is possible by meticulous follow-up. Special attention should be paid in the occurrence of diaphragmatic hernia in patients who frequently receive RFA therapy in the right lobe, which is widely covered by the diaphragm.

The clinical characteristics of diaphragmatic hernia include right upper quadrant abdominal acute pain with dyspnea. Chest radiographic findings are sometimes misdiagnosed as gastrointestinal perforation because the colon gas in the chest wall may be disguised as abdominal free air. Contrast-enhanced CT plays an important role in the diagnosis and in determining if the intruded organs are necrotic. As diaphragmatic hernia requires surgical repair, recent reports demonstrated that laparoscopic simple closure is effective [7]. The laparoscopic approach for an acute abdomen is less invasive and promotes a faster recovery in patients with stable vital signs and no previous medical history of surgery [18]. Timely and accurate diagnosis of this disease is important because these patients have severe liver dysfunction; therefore, colon necrosis leads to poor prognosis even after curative treatment. Once diagnosed, surgical repair is required to prevent intestinal intrusion.

\section{Conclusions}

In conclusion, the present case suggests that frequent RFA therapy may render the right diaphragm fragile due to the frequent thermal damage. Special attention to diagnose delayed complications of RFA, such as diaphragmatic hernia, is warranted in such cases.

\section{Consent}

Written informed consent was obtained from the patient for publication of this case report and accompanying images. A copy of the written consent is available for review by the editor-in-chief of the Journal.

Table 1 Reported cases of diaphragmatic hernia occurring after radiofrequency ablation

\begin{tabular}{|c|c|c|c|c|c|c|c|c|c|}
\hline No. & Author & Year & Age (years) & Sex & Location of HCC & Time from latest RFA (month) & Treatment & Complications & Outcomes \\
\hline 1 & Koda et al. [14] & 2002 & 61 & $\mathrm{~F}$ & sIV & 13 & OS & HCC rupture & Dead \\
\hline 2 & Shibuya et al. [10] & 2006 & 72 & M & Border of sIV and sVIII & 18 & OS & None & Alive \\
\hline 3 & di Francesco et al. [16] & 2008 & 49 & M & Dome of the right lobe & 15 & OS & None & Alive \\
\hline 4 & Yamagami et al. [15] & 2010 & 71 & $\mathrm{~F}$ & sVII & 9 & None & None & Alive \\
\hline 5 & Singh et al. [17] & 2011 & 46 & $\mathrm{~F}$ & Border of sV and sVII & 11 & LS & None & Alive \\
\hline 6 & Nomura et al. [7] & 2014 & 62 & M & sVIII & 96 & LS & None & Alive \\
\hline 7 & Our case & 2016 & 72 & $\mathrm{~F}$ & sVIII & 15 & OS & None & Alive \\
\hline
\end{tabular}

$F$ female, $L S$ laparoscopic surgery, $M$ male, OS open surgery 


\section{Abbreviations}

CT: computed tomography; HCC: hepatocellular carcinoma; LR: liver resection; RFA: radiofrequency ablation; TACE: transarterial chemoembolization.

\section{Competing interests}

The authors declare that they have no competing interests.

\section{Authors' contributions}

TA, HT, and TN performed the operation. HA, TA, NF, TS, MY, and MN managed the perioperative course. TA and TN wrote the manuscript. All the authors read and approved the final manuscript.

\section{Acknowledgements}

This case report is not supported by any grants.

Received: 14 December 2015 Accepted: 3 March 2016

Published online: 14 March 2016

\section{References}

1. Forner A, Llovet JM, Bruix J. Hepatocellular carcinoma. Lancet. 2012;379: 1245-55.

2. Fan ST, Mau Lo C, Poon RT, Yeung C, Leung Liu C, Yuen WK, et al. Continuous improvement of survival outcomes of resection of hepatocellular carcinoma: a 20-year experience. Ann Surg. 2011;253:745-58.

3. Kuroda S, Tashiro H, Kobayashi T, Oshita A, Amano H, Ohdan H. No impact of perioperative blood transfusion on recurrence of hepatocellular carcinoma after hepatectomy. World J Surg. 2012;36:651-8.

4. Imai K, Beppu T, Chikamoto A, Doi K, Okabe H, Hayashi H, et al. Comparison between hepatic resection and radiofrequency ablation as first-line treatment for solitary small-sized hepatocellular carcinoma of $3 \mathrm{~cm}$ or less. Hepatol Res. 2013;43:853-64.

5. Huang J, Yan L, Cheng Z, Wu H, Du L, Wang J, et al. A randomized trial comparing radiofrequency ablation and surgical resection for HCC conforming to the Milan criteria. Ann Surg. 2010;252:903-12.

6. Rhim H, Yoon KH, Lee JM, Cho Y, Cho JS, Kim SH, et al. Major complications after radio-frequency thermal ablation of hepatic tumors: spectrum of imaging findings. Radiographics. 2003;23:123-34. Discussion 34-6.

7. Nomura $R$, Tokumura H, Furihata M. Laparoscopic repair of a diaphragmatic hernia associated with radiofrequency ablation for hepatocellular carcinoma: lessons from a case and the review of the literature. Int Surg. 2014;99:384-90.

8. Wood TF, Rose DM, Chung M, Allegra DP, Foshag LJ, Bilchik AJ. Radiofrequency ablation of 231 unresectable hepatic tumors: indications, limitations, and complications. Ann Surg Oncol. 2000;7:593-600.

9. Livraghi T, Solbiati L, Meloni MF, Gazelle GS, Halpern EF, Goldberg SN. Treatment of focal liver tumors with percutaneous radio-frequency ablation: complications encountered in a multicenter study. Radiology. 2003;226:441-51.

10. Shibuya A, Nakazawa T, Saigenji K, Furuta K, Matsunaga K. Diaphragmatic hernia after radiofrequency ablation therapy for hepatocellular carcinoma. AJR Am J Roentgenol. 2006;186:S241-3.

11. Hasegawa K, Makuuchi M, Takayama T, Kokudo N, Arii S, Okazaki M, et al. Surgical resection vs. percutaneous ablation for hepatocellular carcinoma: a preliminary report of the Japanese nationwide survey. J Hepatol. 2008;49: 589-94.

12. Kim JS, Kim HS, Myung DS, Lee GH, Park KJ, Cho SB, et al. A case of diaphragmatic hernia induced by radiofrequency ablation for hepatocellular carcinoma. Korean J Gastroenterol. 2013:62:174-8.

13. Francica G. Complications of radio-frequency thermal ablation. Radiology. 2001;220:554.

14. Koda M, Ueki M, Maeda N, Murawaki Y. Diaphragmatic perforation and hernia after hepatic radiofrequency ablation. AJR Am J Roentgenol. 2003; 180:1561-2.

15. Yamagami T, Yoshimatsu R, Matsushima S, Tanaka O, Miura H, Nishimura T. Diaphragmatic hernia after radiofrequency ablation for hepatocellular carcinoma. Cardiovasc Intervent Radiol. 2011;34:S115-7.

16. di Francesco F, di Sandro S, Doria C, Ramirez C, laria M, Navarro V, et al. Diaphragmatic hernia occurring 15 months after percutaneous radiofrequency ablation of a hepatocellular cancer. Am Surg. 2008;74(2): 129-32.
17. Singh $\mathrm{M}$, Singh $\mathrm{G}$, Pandey $\mathrm{A}$, Cha $\mathrm{CH}$, Kulkarni S. Laparoscopic repair of iatrogenic diaphragmatic hernia following radiofrequency ablation for hepatocellular carcinoma. Hepatol Res. 2011;41:1132-6.

18. Abe T, Kajiyama K, Harimoto N, Gion T, Nagaie T. Laparoscopic omentectomy for preoperative diagnosis of torsion of the greater omentum. Int J Surg Case Rep. 2012;3:100-2.

\section{Submit your manuscript to a SpringerOpen ${ }^{\circ}$ journal and benefit from:}

- Convenient online submission

- Rigorous peer review

- Immediate publication on acceptance

- Open access: articles freely available online

- High visibility within the field

- Retaining the copyright to your article 